\title{
Synthesis of Isoxazoles and Pyrazoles Containing Pyrimidine Substituted $s$-Triazines
}

\author{
ANUPAMA $^{1}$ and BHAWANI SINGH ${ }^{2, *}$ \\ ${ }^{1}$ Department of Chemistry, Banasthali Vidyapith (Rajasthan)-304022, India \\ ${ }^{2}$ Department of Pure \& Applied Chemistry, University of Kota, \\ Kota (Rajasthan)-324005, India \\ bsyadav@uok.ac.in
}

Received 2 May 2015 / Accepted 18 May 2015

\begin{abstract}
Various chalcones [(E)-1-(4-(4,6-bis(pyrimidine-2-ylamino)-1,3,5-triazine-2-ylamino) phenyl)-3(pyridine-2-yl)prop-2-en-1-one and (E)-3-(pyridine-2-yl)-1-(4-(4-(4-(E)-3-(pyridine-4-yl) acryloyl)phenylamino)-6-(pyrimdine-2-ylamino)-1,3,5-triazine-2-ylamino)phenyl)prop-2-en-1-one] prepared to react with hydroxylamine hydrochloride and hydrazine hydrate to synthesize corresponding isoxazole and pyrazole derivatives.
\end{abstract}

Keywords: Chalcones, Pyrimidine, Isoxazole, Pyrazole, Hydrazinehydrate, Hydroxylamine hydrochloride, Triazine

\section{Introduction}

$s$-Triazines have potential to act as therapeutic agents in the treatment of various fungal and bacterial diseases including some cancers ${ }^{1}$. They also have potential to act as tools of affinity-cleavage reagents for use in molecular biology ${ }^{2}$. Incorporation of isoxazole and pyrazole scaffolds on to the nucleus of $s$-triazine incorporated with pyrimidine derivatives could produce novel analogues with enhanced biological profiles ${ }^{3-7}$. In view of this, it was considered worthwhile to incorporate moieties on to s-triazines to append the above heterocyclic scaffolds.

There has been considerable interest in the pyrazole and isoxazole ring system ${ }^{8}$, both with regard to heterocyclic chemistry and pharmacological activities of several of its derivatives ${ }^{9}$. Substituted pyrazoles, isoxazoles and their analogues have been used as precursors in the synthesis of various biologically active molecules. Fused pyrazoles and isoxazoles play a key role in many biological processes and considerable chemical and pharmacological properties that is why these ring systems are often incorporated into drugs designed for antiviral, antimicrobial, antitumor, antifungal, pesticidal, anticonvulsant, antihistaminic, antibiotic, antidepressant and CNS regulant ${ }^{10-12}$ etc. 


\section{Experimental}

\section{Materials and Methods}

All the $s$-triazine derivatives were synthesized by following the under mentioned procedure. Intermediates (1.1) and (1.4) have been synthesized in our laboratory and were checked by elemental analysis, IR and ${ }^{1} \mathrm{H}$ NMR, ${ }^{13} \mathrm{C}$ NMR spectra and mass spectra data.

Structures of all compounds were established on the basis of elemental analysis (Table 1), IR and ${ }^{1} \mathrm{H}$ NMR, ${ }^{13} \mathrm{C}$ NMR spectra and mass spectra data. Physical data of all the compounds were found to be consistent to the structures assigned to these molecule. Melting points were determined in open glass capillaries and are uncorrected. IR spectra were recorded on $\mathrm{KBr}$ (SHIMADZU) FTIR-8400S. ${ }^{1} \mathrm{H}$ NMR \& ${ }^{13} \mathrm{C}$ NMR spectra were recorded on model AVANCE II 400 (BRUKER) using DMSO as solvent and TMS as an internal reference. Chemical shift are expressed in $\delta \mathrm{ppm}$. All chemicals and reagents were purchased from commercial sources.

Table 1. Physical and analytical data of compounds

\begin{tabular}{|c|c|c|c|c|c|c|c|c|}
\hline \multirow[b]{2}{*}{$\begin{array}{l}\text { S. } \\
\text { No. }\end{array}$} & \multirow[b]{2}{*}{$\begin{array}{c}\text { Compd. } \\
\text { No. }\end{array}$} & \multirow[b]{2}{*}{$\begin{array}{l}\text { Molecular } \\
\text { Formula }\end{array}$} & \multirow[b]{2}{*}{ M.W. } & \multirow[b]{2}{*}{ M.P. } & \multirow[b]{2}{*}{$\begin{array}{c}\text { Yield } \\
\%\end{array}$} & \multicolumn{3}{|c|}{ Elemental Analysis } \\
\hline & & & & & & $\begin{array}{c}\text { (cal./exp) } \\
\text { C }\end{array}$ & $\begin{array}{c}\text { (cal./exp) } \\
\mathrm{H}\end{array}$ & $\begin{array}{c}\text { (cal./exp) } \\
\mathrm{N}\end{array}$ \\
\hline 1. & 1.2 & $\mathrm{C}_{26} \mathrm{H}_{20} \mathrm{~N}_{12} \mathrm{O}$ & 516.52 & $270-275$ & 85 & $60.46 / 60.39$ & $3.90 / 3.92$ & $32.54 / 32.52$ \\
\hline 2. & 1.3 & $\mathrm{C}_{26} \mathrm{H}_{21} \mathrm{~N}_{13}$ & 515.53 & $260-265$ & 35 & $60.57 / 60.52$ & $4.11 / 4.13$ & $35.32 / 35.39$ \\
\hline 3. & 1.5 & $\mathrm{C}_{35} \mathrm{H}_{24} \mathrm{~N}_{12} \mathrm{O}_{2}$ & 644.64 & $272-277$ & 65 & $65.21 / 65.19$ & $3.75 / 3.74$ & $26.07 / 26.11$ \\
\hline 4. & 1.6 & $\mathrm{C}_{35} \mathrm{H}_{26} \mathrm{~N}_{14}$ & 642.67 & $268-272$ & 42 & $65.21 / 65.39$ & $4.08 / 4.11$ & $30.51 / 30.49$ \\
\hline
\end{tabular}

\section{General Procedures}

Preparation of (R)-N2-(4-(pyridine-2-yl)-4H-1,2-oxazin-4-yl)phenyl)-N4,N6di(pyrimidin-2-yl)-1,3,5triazine-2,4,6-triamine (1.2)

A mixture of hydroxylamine hydrochloride $(2.78 \mathrm{~g}, 0.04 \mathrm{~mol})$ was added to sodium methoxide $(3.24 \mathrm{~g}, 0.06 \mathrm{~mol})$ in absolute methanol $(30 \mathrm{~mL})$ and stirred for $10 \mathrm{~min}$. (E)-1-(4(4,6-bis(pyrimidine-2-ylamino)-1,3,5-triazine-2-ylamino)phenyl)-3-(pyridine-2-yl)prop-2-

en-1-one (1.1) (1.95 g, $0.004 \mathrm{~mol}$ ) was added and the mixture was refluxed for $5 \mathrm{~h}$. Most of the methanol was evaporated under reduced pressure and the mixture was poured in to ice cold water. The solid separated was then kept over night. Later on it was filtered, washed with diethyl ether \& recrystalization from ethanol to give dark chocolate colour compound. Yield: 85\%, mp.-270-275 ${ }^{\circ} \mathrm{C}$. IR (KBr) cm- ${ }^{1}$ : 13450 [N-H str.] 3050 [C-H str. Ar.H], 1590 [C $=\mathrm{C}$ str.], 1580, 1602 [C=N str.], 1260 [C-N str.], 890 [C-O-N str.]. ${ }^{1} \mathrm{H}$ NMR (DMSO) $\delta$ : ppm 8.54 [d, 2H, $(\mathrm{CH})$ (pyridine)], $8.45[\mathrm{~d}, 4 \mathrm{H},(\mathrm{CH})$ (pyrimidine)], $7.47[\mathrm{~m}, 2 \mathrm{H},(\mathrm{CH})$ (pyridine)], 7.04 [d, 1H, $(\mathrm{CH})$ (ethylene)], 6.88-7.33 [m, 3H, $(\mathrm{CH})$ (benzene)], 4.0 [s, 3H, (aromatic C-NH)], 3.5 [t, 1H, (methine near isoxazole ring)].

Preparation of N2-(4-(6-(pyridine-2-yl)-1,4-dihydropyridazin-4-yl)phenyl)-N4,N6di(pyrimidin-2-yl)-1,3,5-triazine-2,4,6-triamine (1.3)

(E)-1-(4-(4,6-bis(pyrimidine-2-ylamino)-1,3,5-triazine-2-ylamino)phenyl)-3-(pyridine-2yl)prop-2-en-1-one (1.1) $(1.95 \mathrm{~g}, 0.004 \mathrm{~mol})$ and hydrazine hydrate $(2.50 \mathrm{~g}, 0.04 \mathrm{~mol})$ was heated under reflux for $8 \mathrm{~h}$ in $30 \mathrm{~mL}$ absolute ethanol. The solvent was removed and the residue was extracted with $20 \mathrm{~mL}$ of chloroform. On removal of the solvent a dark crystalline solid was obtained. Yield: $35 \%, \mathrm{mp} .260-265^{\circ} \mathrm{C}$. IR $(\mathrm{KBr}) \mathrm{cm}^{-1}: 3456$ [N-H str.], 
3092 [N-H str., pyrazole ring], 2978 [C-H str. Ar.H], 1681 [C=C str.], 1587-1608 [C=N str.], 1174 [C-N str.]. ${ }^{1} \mathrm{H}$ NMR (DMSO) $\delta: 8.56$ [m, 2H, $(\mathrm{CH})$ (pyridine)], 8.45-8.54 [m, $4 \mathrm{H},(\mathrm{CH})$ (pyrimidine) ] 7.47-7.50 [m, 2H, $(\mathrm{CH})$ (pyridine) $], 7.32-7.42[\mathrm{~d}, 2 \mathrm{H},(\mathrm{CH})$ (benzene)], 6.83-6.84 [m, 2H, $(\mathrm{CH})$ (pyrimidine)], 6.81-6.82 [d, 2H, $(\mathrm{CH})$ (benzene)], $5.71[\mathrm{~s}, 1 \mathrm{H},(\mathrm{CH})$ (ethylene)], $4.13[\mathrm{~s}, 3 \mathrm{H},($ aromatic $\mathrm{NH})], 3.69[\mathrm{t}, 1 \mathrm{H}$, (methine attached to pyrazole ring)]. $\mathrm{MS}(\mathrm{m} / \mathrm{z} \%): 284.3(100.00 \%), 308.2(23 \%), 516.5\left(\mathrm{M}^{+}, 28 \%\right), 517.2(7 \%)$.

Preparation of N2-(4-(5-(pyridine-3-yl)isoxazol-3-yl)phenyl)-N4-(4-(5-(pyridine-2yl)isoxazol-3-yl)phenyl)-N6-(pyrimidin-2-yl)-1,3,5-triazine-2,4,6-triamine (1.5)

A mixture of hydroxylamine hydrochloride $(2.78 \mathrm{~g}, 0.04 \mathrm{~mol})$ was added to sodium methoxide (3.24 g, $0.06 \mathrm{~mol})$ in absolute methanol $(30 \mathrm{~mL})$ and stirred for $10 \mathrm{~min}$. (E)-3(pyridine-2-yl)-1-(4-(4-(4-(E)-3-(pyridine-2-yl)acryloyl)phenylamino)-6-(pyrimdine-2-yl amino)-1,3,5-triazine-2-ylamino)phenyl)prop-2-en-1-one (1.4) (1.23 g, $0.002 \mathrm{~mol})$ was added and the mixture was refluxed for $5 \mathrm{~h}$. Most of the methanol was evaporated under reduced pressure and the mixture was poured in to ice cold water.The solid separated was kept overnight. Then it was filtered, washed with diethyl ether \& recrystalized from ethanol. Yield: $65 \%$, mp. $272-277{ }^{0} \mathrm{C}$. IR $(\mathrm{KBr}) \mathrm{cm}^{-1}: 3320$ [N-H str.] 3010 [C-H str. Ar.H], 1560 [C=C str.], 1610, 1520 [C=N str.], 1210 [C-N str.], 885 [C-O-N str.]. ${ }^{1} \mathrm{H}$ NMR (DMSO) $\delta$ : $9.24[\mathrm{~s}, 1 \mathrm{H},(\mathrm{CH})$ (pyridine)], 8.42-8.75 [m, 3H, $(\mathrm{CH})$ (pyridine)] $8.45[\mathrm{~d}, 2 \mathrm{H},(\mathrm{CH})$ (pyrimidine)], 7.57-7.99 [m, 3H, $(\mathrm{CH})$ (pyridine)], 7.54[d, 2H, $(\mathrm{CH})$ (benzene)], 6.93 [t, 1H, $(\mathrm{CH})$ (pyrimidine)], 6.75 [d, 2H, $(\mathrm{CH})$ (isoxazole) ], 6.69 [d, 2H, $(\mathrm{CH})$ (benzene)], 4.0 [s, 3H, (aromatic C-NH)].

Preparation of N2-(4-(5-(pyridine-3-yl)-1H-pyrazol-3-yl)phenyl)-N4-(4-(5-(pyridine2-yl)-1H-pyrazol-3-yl)phenyl)-N6-(pyrimidin-2-yl)-1,3,5-triazine-2,4,6-triamine (1.6)

(E)-3-(pyridine-3-yl)-1-(4-(4-(4-(E)-3-(pyridine-2-yl) acryloyl) phenylamino)-6-( pyrimdine-2ylamino)-1,3,5-triazine-2-ylamino )phenyl )prop-2-en-1-one (1.4) $(1.23 \mathrm{~g}, 0.002 \mathrm{~mol})$ and hydrazine hydrate $(2.50 \mathrm{~g}, 0.04 \mathrm{~mol})$ was heated under reflux for $8 \mathrm{~h}$ in $30 \mathrm{~mL}$ absolute ethanol and then cooled, the residual material was filtered off and re-crystallised from DMF/water.

Yield: $42 \%$, mp.-268-272 ${ }^{\circ} \mathrm{C}$. IR (KBr) cm ${ }^{-1}: 3321$ [N-H str.], 3200 [N-H str. pyrazole ring], 2981 [C-H str., ArH], 1627 [C=C str.], 1550, 1660 [C=N str.], 1352 [C-N str.]. ${ }^{1} \mathrm{H}$ NMR (DMSO) $\delta: 12.70$ [d, 2H, $(\mathrm{CH})$ (pyrazole)], 9.28 [s, 1H, $(\mathrm{CH})$ (pyridine)], 8.46-8.96 [d, $2 \mathrm{H},(\mathrm{CH})$ (pyridine)], 8.93,8.94 [d, 2H, $(\mathrm{CH})$ (pyridine)], 8.92-8.93 [d, 2H, $(\mathrm{CH})$ (pyrimidine)], 7.92-7.99 [d, 2H, $(\mathrm{CH})$ (pyridine)], 7.85 [d, 1H, $(\mathrm{CH})$ (pyridine)], 7.10-7.65 [d, 2H, $(\mathrm{CH})_{2}$ (benzene)], $6.90[\mathrm{~d}, 1 \mathrm{H},(\mathrm{CH})$ (pyrimidine) $], 6.89$ [s, 1H, $(\mathrm{CH})$ (pyrazole)], 6.89 [s, 1H, $(\mathrm{CH})$ (pyrazole)], $6.89[\mathrm{~m}, 2 \mathrm{H},(\mathrm{CH})$ (benzene)], 4.10-4.11 [s, 3H, aromatic $\mathrm{NH}]$. MS (m/z\%): 282.3(100.00), 301.3(35.0\%) , 260.3(28\%), 550.1(13\%), 643.2( $\left.\mathrm{M}^{+}, 16 \%\right)$

\section{Results and Discussion}

In the present work, pyrazole and isoxazole derivatives were obtained by the cyclocondensation of chalcones from their reaction with hydrazine hydrate and hydroxylamine hydrochloride respectively. A stepwise synthesis of the compounds is depicted by the schemes 1 and 2. The strategy shown in the provided schemes was formulated with the idea in mind to incorporate the biologically active pyrazole and isoxazole ring in the given chalcones, in order to enhance their biological properties for pharmacological use. Chalcones shown in the schemes were synthesized at different temperature conditions and which were further reacted with hydroxylamine hydrochloride and hydrazine hydrate in order to produce more biologically and pharmacologically active 
compounds. Compounds 1.2-1.3 has one isoxazole and pyrazole ring while in compounds $1.5 \&$ compound 1.6, there are two isoxazole and pyrazole rings which surprisingly enhances the biological and pharmacological activities of the concerned compound.

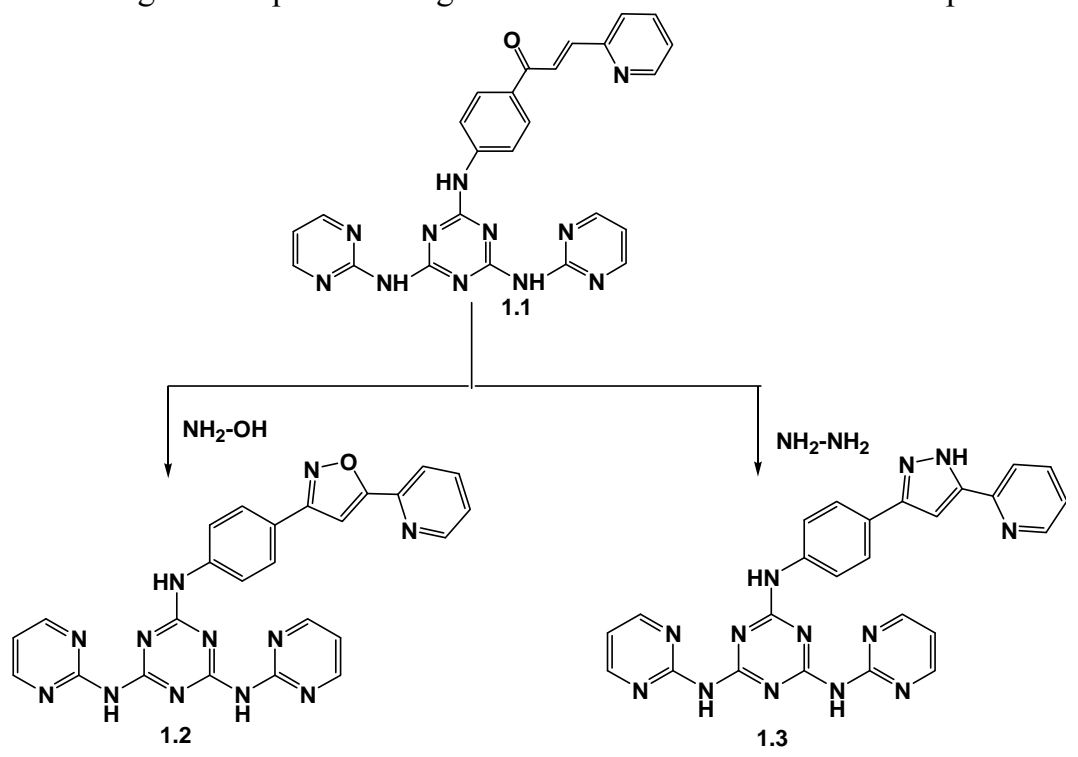

Scheme 1. Synthesis mono-isoxazoles and pyrazoles of s-triazines<smiles>Cc1nc(Nc2ccc(C(=O)/C=C/c3ccccn3)cc2)nc(Nc2ccc(C(=O)/C=C/c3ccccn3)cc2)n1</smiles>

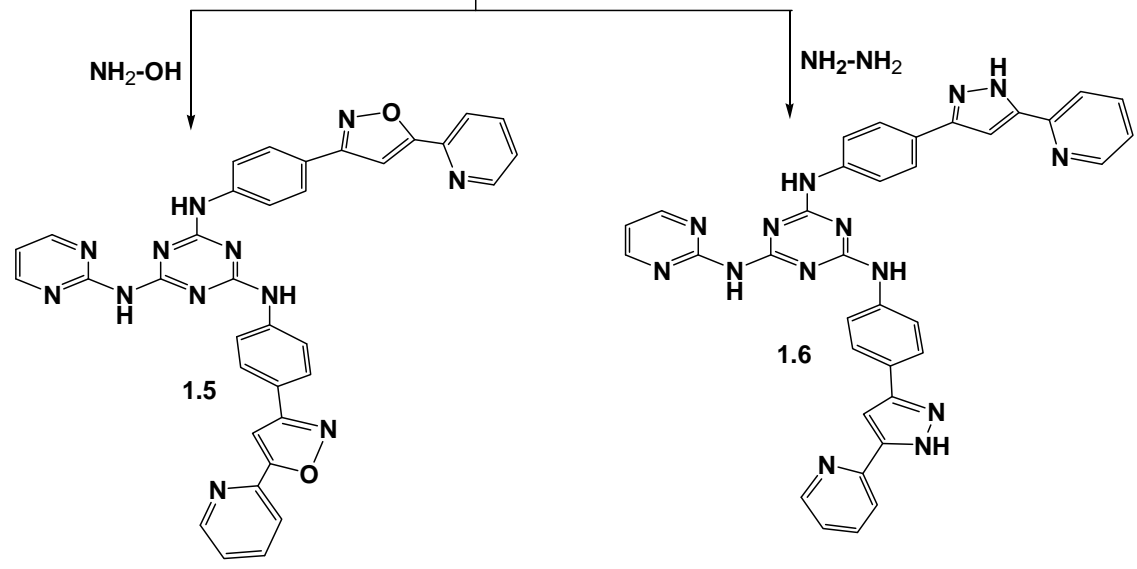

Scheme 2. Synthesis of bis-isoxazoles and pyrazoles of s-triazines 


\section{Acknowledgement}

The author is thankful to Banasthali Vidyapith for providing facility for research and SAIF Punjab University, Chandigarh for providing spectra for the research work.

\section{References}

1. Vyas D D, Tala S D and Dhuhuk M F, J Ind Chem Soc., 2007, 84, 1140.

2. Solanki P K, Burton G, Clarke G J, Douglas J D and Etonglin A J, J Antibiot., 1996, 49, 1266-1274.

3. Grandberg I I, Krokhina N F and Kondrat'ev M N, Pharm Chem., 1968, 2(7), 372-376.

4. Beregi H P, Douarec L and Claude J, Biphenylyl pyrazole compounds. US Pat 1973, 3725432.

5. Pozgan F, Kranjc K, Kepe V, Polanc S and Kocevar M, ARKIVOC, 2007, (iii), 97-111.

6. Doshi R, Kathara P and Parekh H, Indian J Chem., 1999, 38, 348-352.

7. Valentina M, Hamilton M M, Long M, Crane C M and Termin A P, Syntheses, 2002, 34, 1669-1674.

8. Singh G, Ila H and Junjappa H, J Chem Soc Perkin Trans., 1987, 1, 1945-1949; DOI:10.1039/P19870001945

9. Mirzaei Y R, Balasubramaniam T N, Lefler B J and Natale N R, J Heterocyclic Chem., 1990, 27(7), 2001-2004; DOI:10.1002/jhet.5570270729

10. Sheng S R, X L Liu, Q Xu and Song C S, Synthesis, 2003, 2763-2764.

11. Cecchi L, De Sarlo F and Machetti F, Eur J Org Chem., 2006, 21, 4852-4860; DOI:10.1002/ejoc.200600475

12. Hasen T V, Wu P and Fokin V V, J Org Chem., 2005, 70(19), 7761-7764; DOI:10.1021/jo050163b 